\title{
Geographic variations in adherence to and persistence with adjuvant hormonal therapy for the privately insured women aged 18-64 with breast cancer in Texas
}

Jung Hyun Kim ( $\nabla$ junghyun.kim3@rutgers.edu )

Rutgers: Rutgers The State University of New Jersey https://orcid.org/0000-0003-4248-3760

\section{Suja S. Rajan}

The University of Texas Health Science Center at Houston

Xianglin L. Du

The University of Texas Health Science Center at Houston

Luisa Franzini

University of Maryland School of Public Health

Sharon H. Giordano

University of Texas MD Anderson Cancer Center

Robert O. Morgan

The University of Texas Health Science Center at Houston

\section{Research Article}

Keywords: adjuvant hormonal therapy, breast cancer, treatment adherence and persistence

Posted Date: April 19th, 2021

DOI: https://doi.org/10.21203/rs.3.rs-224248/v1

License: (c) (i) This work is licensed under a Creative Commons Attribution 4.0 International License.

Read Full License 


\section{TITLE PAGE}

\section{Title}

Geographic variations in adherence to and persistence with adjuvant hormonal therapy for the privately insured women aged 18-64 with breast cancer in Texas

\section{Authors}

Junghyun Kim, PhD, MPH

Center for Pharmacoepidemiology and Treatment Science (PETS)

Rutgers, The State University of New Jersey

112 Paterson St

New Brunswick, NJ 08901

Junghyun.kim3@rutgers.edu

Suja S. Rajan, PhD

Associate professor, Management, Policy \& Community Health

School of Public Health, University of Texas Health Science Center at Houston

1200 Herman Pressler Street

Houston, TX 77030

Suja.S.Rajan@uth.tmc.edu

Xianglin L. Du, MD, PhD

Professor, Epidemiology, Human Genetics \& Environmental Sciences

School of Public Health, University of Texas Health Science Center at Houston

1200 Herman Pressler Street

Houston, TX 77030

Xianglin.L.Du@uth.tmc.edu

1) P a g e 
Luisa Franzini, $\mathrm{PhD}$

Professor, Health Services Administration

School of Public Health, University of Maryland

4200 Valley Drive

College Park, Maryland 20742-2611

franzini@umd.edu

Sharon H. Giordano, MD, MPH

Department Chair, Department of Health Services Research

The University of Texas MD Anderson Cancer Center

1515 Holcombe Blvd.

Houston, Texas 77030

sgiordan@mdanderson.org

Robert O. Morgan, PhD

Department Chair, Management Policy and Community Health

School of Public Health, University of Texas Health Science Center at Houston

1200 Herman Pressler Street

Houston, TX 77030

Robert.O.Morgan@uth.tmc.edu

2 | P a g e 


\begin{abstract}
Purpose: Objective of this study is to examine the geographical patterns of adjuvant hormonal therapy adherence and persistence and the associated factors in insured women aged 18-64 with early breast cancer in Texas. Methods: A retrospective cohort study was conducted by using claims data for population insured by Blue Cross Blue Shield of Texas (BCBSTX) from the year 2008 to 2013. Women diagnosed with early breast cancer who were taking tamoxifen or aromatase inhibitors (AIs) for adjuvant hormonal therapy with at least one prescription claim, from January 1, 2008 to December 31, 2012, and were enrolled through 2013, were identified. Adherence to adjuvant hormonal therapy and persistence on adjuvant hormonal therapy were calculated as outcome measures. Women without a gap between two consecutive dispensed prescriptions of at least 90 days in medication were considered as persistently taking the medications. Patient-level multivariate logistic regression models with repeated regional-level adjustments were used to determine the geographical variations and patient-level, provider-level, and area-level factors that were associated with adjuvant hormonal therapy adherence. Results: Of the 938 women in the cohort, $627(66.8 \%)$ initiated adjuvant hormonal therapy. Most of the smaller HRRs have significantly higher or lower rates of treatment adherence and persistence rates relative to the median regions. The use of AHT varies substantially from one geographical area to another, especially for adherence, with an approximately two-fold difference between the lowest and highest areas and area-level factors were found to be significantly associated with the compliance of AHT. Conclusions: There are geographical variations in AHT adherence and persistence in Texas. Patient-level and area-level factors have significant associations explaining these patterns.
\end{abstract}




\section{Geographic variations in adherence to and persistence with adjuvant hormonal therapy for the privately insured women aged 18-64 with breast cancer in Texas}

\section{INTRODUCTION}

Breast cancer is the most commonly diagnosed cancer and second leading cause of death in women in Texas, representing $29.5 \%$ of all new malignant cancers diagnosed in women [1]. An average of 2,849 Texas women with breast cancer died annually from 2012-2016 [1]. In 2019, the expected breast cancer deaths were 3,213 and the total hospital charges for breast cancer hospitalizations were approximately \$252 million, and the estimated total expenditure for breast cancer care was highest for physician care at about \$29.9 million compared to inpatient or outpatient hospital care [1].

Significant variations in breast cancer care, including non-adherence to hormonal therapy, and/or early discontinuation of hormonal therapy, arise frequently and may impact survival [2, 3, 4]. Many patients fail to take the prescribed drug on a daily basis (non-adherence), or to continue of taking medication over a long-term period (persistence of use). Lack of compliance with prescribed adjuvant hormonal medication frequently results in treatment failure $[3,4,5]$. Adjuvant systemic hormonal therapy is a crucial procedure for maximizing the benefits of treatment. Guideline-concordant optimal adherence to, and persistence with therapy increases the likelihood that patients with hormonal sensitive breast cancer can expect better outcomes.

This study examines rates of adjuvant hormonal therapy compliance for patients with breast cancer aged between 18-64 across regions of Texas. Some studies have addressed regional variation in breast cancer initial treatment type [6-12]. However, no study has compared adjuvant hormonal therapy adherence and persistence rates to determine whether geographical variations are seen among regions. Further, the primary predictors for observed patterns of quality adjuvant hormonal therapy have not been determined. There are mixed findings among studies for various individual and clinical characteristics, with estimates of geographic variation and provider/area level factors frequently missing. It is unclear whether similar factors affect hormonal therapy use among younger population as among older patients [13-22].

We compare actual endocrine therapy compliance rates by Hospital Referral Regions across Texas. Texas is a particularly useful state in which to examine regional variation, because it is large and diverse demographically 
and geographically. It is the second most populous U.S. state, with 27 million people in 2014 [23]. The state has several large urban and extensive rural areas and an ethnically diverse population. Some regions have access to large teaching hospitals, while many do not.

The purpose of this study is to explore the geographic variation by Hospital Referral Region in Texas in adherence to and persistence with adjuvant hormonal therapy use among privately insured women with breast cancer and its predictors.

\section{METHODS}

\section{Data}

This study employed a retrospective population-based cohort using enrollment and claims data for the population insured by Blue Cross Blue Shield of Texas (BCBSTX) from the year 2008 to 2013. The dataset includes a claims file with all the claims (institutional, professional and pharmacy claims) processed by the BCBSTX and a member enrollment file for approximately 5.6 million BCBSTX members from the year 2008 to 2013. This is approximately one-third of the private insurance population in Texas. The data were obtained through the University of Texas School of Public Health/ BCBSTX Research Program in Payment Systems and Policy. The socioeconomic status of the areas where patients reside was obtained from the Census 2010 summary file 3 (SF3). Area-level characteristics were obtained from the 2012-2013 Health Resources and Services Administration's Area Resource File (ARF).

\section{Study cohort description}

The study cohort includes all women aged between 18 to 64 and diagnosed with primary breast cancer (ICD-9 code, 174.x) and/or in situ breast cancer (ICD-9 code, 233.x) between June 1, 2008, and December 31st, 2012. All women in the target population were continuously enrolled after the index date and followed for at least one and up to five years after their diagnosis.

Patients were included if they were enrolled in preferred provider organizations ( $\mathrm{PPO}$ and $\mathrm{PPO}+$ ) plan type, had drug benefits with the BCBSTX during the study period, and resided in a Texas Hospital Referral Region (HRR). We included patients who received at least one prescription claim for oral hormonal therapy such as tamoxifen, anstrozole, exemestane, or letrozole after the index date and before disenrollment. We used the generic 
product index (GPI) code to identify all the maintenance adjuvant hormonal therapy (AHT) medications of interest from the pharmacy claims data.

\section{Outcome}

This study examined the rates of adherence and persistence of adjuvant hormonal therapy for treating breast cancer by hospital referral regions in Texas.

Adherence was determined using a medication possession ratio (MPR), defined as the ratio of days covered by the amount of medication supplied, of $80 \%$ or greater during a defined period by year [14-22, 24-28].

Persistence was defined as the absence of a gap of 90 or more days between two consecutive dispensed prescriptions during the time from initiation to discontinuation of the AHT therapy. The use of 90 days for defining persistence will be primary gap definition in this study [18]. To account for potential variation in persistence, sensitivity analysis was conducted for the different gaps (60 and 180 days) in therapy defining the persistence measure $[18,22,26-28]$.

\section{Patient-level, Provider-level and Area-level characteristics}

Patient-level variables included age at diagnosis, education, poverty, percent Hispanic and Latino population, year of diagnosis, whether initiating the therapy within a year of breast cancer diagnosis, health care utilization (a total number of outpatient visits and inpatient days during 6 months prior breast cancer diagnosis and each subsequent year of therapy ), Charlson comorbidity that weights a range of comorbid conditions for a patient with a total of 22 conditions including heart disease, kidney disease, lung disease, AIDS, or cancer [27-29] as well as distance to care. Age was categorized into the intervals $<40,40-44,45-49,50-54,55-59$, and 60-64.

Patient socioeconomic status was measured at the zip code level, which includes the level of poverty in the area, level of educational attainment, and percent of the population which is non-white. Each of four equal groups was divided according to the distribution of values of those variables. Zip code level variables were measured at the Zip Code Tabulation Area (ZCTA) level and assigned to the patient using the patient zip code and the zip code to ZCTA crosswalk available on the Dartmouth Atlas of Health Care website. Health care utilization was coded as "0" 
or "1" with "1" indicating any number of outpatient visits or inpatient stays during the study period of each individual.

We determined the hospital referral region (HRR) that each patient resided in. Hospital Referral Region (HRR) represents the regional health care markets for their respective tertiary medical centers [30]. HRR unit analysis was conducted to describe geographic variation of adjuvant hormonal therapy adherence and persistence in Texas. The U.S. is divided into 306 HRRs, and 22 are in Texas.

For provider-area characteristics (defined as County), the total number of hospitals, the number of hospital admissions, and hospital beds as a proxy of volume of hospital were estimated from the area resource file, with the most recent years of data were used. The county-level data from the ARF file was converted to HRR-level using county-HRR crosswalk that weights the population in each county. Area level characteristics also include numbers of oncology subspecialty (radiologists) from the ARF and numbers of oncology providers in area. The number of oncologists in area were calculated over the one calendar year for each hospital.

\section{Statistical Analysis}

Patient, provider, and area characteristics were summarized using percentages for categorical variables and means and standard deviations (SDs) for continuous variables. To examine geographic variation in adherence and persistence to the adjuvant hormonal therapy, we reported the mean and median adherence and persistence rates for breast cancer adjuvant hormonal therapy in our study across in Texas, as well as the lowest and highest compliance rates by HRR.

The adherence rates for each HRR were calculated by dividing the number of people who were already defined whether they were adhere or not adhere to the treatment by the number of adherence counts in the HRR. 
We calculated the coefficient of variation and the index of variation to examine variation in adherence to guideline recommended care among HRRs in Texas.

The adherence by HRR were described in Table 2. For persistence by HRR, various lengths of treatment gaps were applied in Table 3. We listed the name of the HRR associated with each reported rate, so that we can look for similarities and differences in patterns of endocrine therapy care across regions in Texas.

To examine regional variation of adherence to and persistence of the hormonal therapy, we used patientlevel logistic regression models with region of residence as a 22-level fixed effect. Differences were tested between each region and the median region for each outcome (adherence and persistence of therapy).

\section{RESULTS}

A total of 938 patients who had incident early breast cancer between the years 2008 to 2012 were identified. More than half of women had breast-conserving surgery (58.74\%) and received radiation (97.12\%). Most women were 45-59 years old at diagnosis, lived regions with neighborhood had a high school education, where people with below poverty line (Table 1). Of the 938 women with breast cancer, 627 (66.8\%) initiated adjuvant hormonal therapy. Figure 1 addresses steps of the study inclusion and exclusion criteria.

Table 1 Descriptive statistics for the study cohort

\begin{tabular}{ll}
\hline Characteristic & $\mathbf{N}(\mathbf{\%})$ \\
\hline Adjuvant hormonal therapy & $627(66.77)$ \\
Initiated therapy & $332(52.95)$ \\
$\quad$ Tamoxifen only & $295(47.05)$ \\
$\quad$ Aromatase inhibitor only & $311(33.23)$ \\
Did not initiate therapy & \\
\hline Cancer Treatment & $551(58.74)$ \\
Breast conserving surgery & $317(33.80)$ \\
Mastectomy & $565(60.23)$ \\
Chemotherapy & $911(97.12)$ \\
Radiation therapy
\end{tabular}




\begin{tabular}{|c|c|}
\hline \multicolumn{2}{|c|}{ Year of diagnosis } \\
\hline 2008 & $225(23.99)$ \\
\hline 2009 & $223(23.77)$ \\
\hline 2010 & $199(21.22)$ \\
\hline 2011 & $170(18.12)$ \\
\hline 2012 & $121(12.90)$ \\
\hline \multicolumn{2}{|c|}{ Age at diagnosis } \\
\hline$<40$ & $45(4.80)$ \\
\hline $40-44$ & $82(8.74)$ \\
\hline $45-49$ & $176(18.76)$ \\
\hline $50-54$ & $234(24.95)$ \\
\hline $55-59$ & $312(33.26)$ \\
\hline $60-64$ & $89(9.49)$ \\
\hline \multicolumn{2}{|c|}{ Neighborhood, \% nonwhite population } \\
\hline$<10 \%$ & $108(11.51)$ \\
\hline $10-24 \%$ & $461(49.15)$ \\
\hline $25-50 \%$ & $273(29.10)$ \\
\hline$\geq 50 \%$ & $96(10.23)$ \\
\hline \multicolumn{2}{|c|}{ Percent of population ages 25 and older without a high school education } \\
\hline$<25 \%$ & $733(78.14)$ \\
\hline$\geq 25 \%$ & $205(21.86)$ \\
\hline \multicolumn{2}{|c|}{ Neighborhood, \% below poverty level } \\
\hline$<20 \%$ & $705(75.16)$ \\
\hline$\geq 20 \%$ & $233(24.84)$ \\
\hline Distance & \\
\hline
\end{tabular}

9| Pag e 


\begin{tabular}{lc}
\hline less than 5 mile & $273(29.10)$ \\
$5-10$ mile & $160(17.06)$ \\
$10-35$ mile & $292(31.13)$ \\
$35-100$ mile & $129(13.75)$ \\
$>100$ mile & $84(8.96)$ \\
Comorbidity at diagnosis, mean (SD) & $1.27(1.96)$ \\
Health care utilization at diagnosis & $1.73(2.69)$ \\
Outpatient visits in prior 6 months, mean (SD) & $1.45(1.39)$ \\
\hline Inpatient days in prior 6 months, mean (SD) & \\
\hline
\end{tabular}

10| P a g e 
Figure 1 Step of Inclusion/Exclusion Criteria

\begin{tabular}{|l|}
\hline $\begin{array}{l}\text { Identified women } 18 \text { years and older with at least one diagnosis of breast } \\
\text { cancer between July } 2008 \text { and December } 2012 .\end{array}$ \\
Identified women had a claim with a procedure code for lumpectomy, \\
partial mastectomy, or mastectomy followed by at least one claim for \\
priotherapy or had at least two outpatient claims on different dates with a \\
primary diagnosis of breast cancer \\
\hline \\
Included patients who received at least one prescription claim for adjuvant \\
hormonal therapy and at least 12 months of continuous enrollment \\
following after diagnosis
\end{tabular}

Table 2 provided descriptive statistics on mean adjuvant hormonal therapy adherence and persistence rates by the HRRs, as well as information with median, minimum, and maximum therapy adherence and persistence rates. We reported the number of people who received endocrine therapy in each HRR in the table.

11 | P a g e 
The adherence rate is lowest in women from the HRR of San Angelo (54\%) and highest in women from Victoria (100\%). The median region of the adherence rate is Dallas $(79 \%)$ and the mean rate for Texas was $79 \%$. The median rate of persistence for 90 -day gap in therapy is $81 \%$ in Dallas, the mean rate for Texas was $75 \%$. The persistence rate is lowest in the HRR of Beaumont (50\%) and highest in Bryan, San Angelo, Temple, and Victoria (100\%). Figure 2 and 3 show the Texas maps with HRRs color-coded based on the adherence and persistence rates. The darker the color the higher the compliance to the treatment.

Table 2. Mean AHT adherence and persistence rates by HRR

N Adherence by HRR

90-day gap persistence by HRR

Hospital Referral Region

\begin{tabular}{|c|c|c|c|c|c|}
\hline Abilene & 13 & 0.7 & & 0.89 & \\
\hline Amarillo & 18 & 0.78 & & 0.80 & \\
\hline Austin & 78 & 0.77 & & 0.86 & \\
\hline Beaumont & 13 & 0.73 & & 0.50 & $\begin{array}{c}\text { Minimum } \\
\text { region }\end{array}$ \\
\hline Bryan & 12 & 0.94 & & 1 & $\begin{array}{c}\text { Maximum } \\
\text { region }\end{array}$ \\
\hline Corpus Christi & 6 & 0.61 & & 0.6 & \\
\hline Dallas & 244 & 0.79 & Median region & 0.81 & Median region \\
\hline El Paso & 15 & 0.82 & & 0.78 & \\
\hline Fort Worth & 74 & 0.83 & & 0.80 & \\
\hline Harlingen & 12 & 0.71 & & 0.88 & \\
\hline Houston & 243 & 0.81 & & 0.80 & \\
\hline Longview & 19 & 0.77 & & 0.87 & \\
\hline Lubbock & 29 & 0.68 & & 0.89 & \\
\hline McAllen & 16 & 0.66 & & 0.67 & \\
\hline Odessa & 31 & 0.71 & & 0.90 & \\
\hline
\end{tabular}




\begin{tabular}{|c|c|c|c|c|c|}
\hline San Angelo & 9 & 0.54 & $\begin{array}{l}\text { Minimum } \\
\text { region }\end{array}$ & 1 & $\begin{array}{c}\text { Maximum } \\
\text { region }\end{array}$ \\
\hline San Antonio & 66 & 0.84 & & 0.73 & \\
\hline Temple & 2 & 0.8 & & 1 & $\begin{array}{c}\text { Maximum } \\
\text { region }\end{array}$ \\
\hline Tyler & 25 & 0.76 & & 0.78 & \\
\hline Victoria & 1 & 1 & $\begin{array}{l}\text { Maximum } \\
\text { region }\end{array}$ & 1 & $\begin{array}{c}\text { Maximum } \\
\text { region }\end{array}$ \\
\hline Waco & 10 & 0.96 & & 0.80 & \\
\hline Wichita Falls & 3 & 0.93 & & 1 & $\begin{array}{c}\text { Maximum } \\
\text { region }\end{array}$ \\
\hline
\end{tabular}

Mean of TX $=0.79 ; 0.75$ 
Figure 2 Adherence among Texas Hospital Referral regions (HRRs)

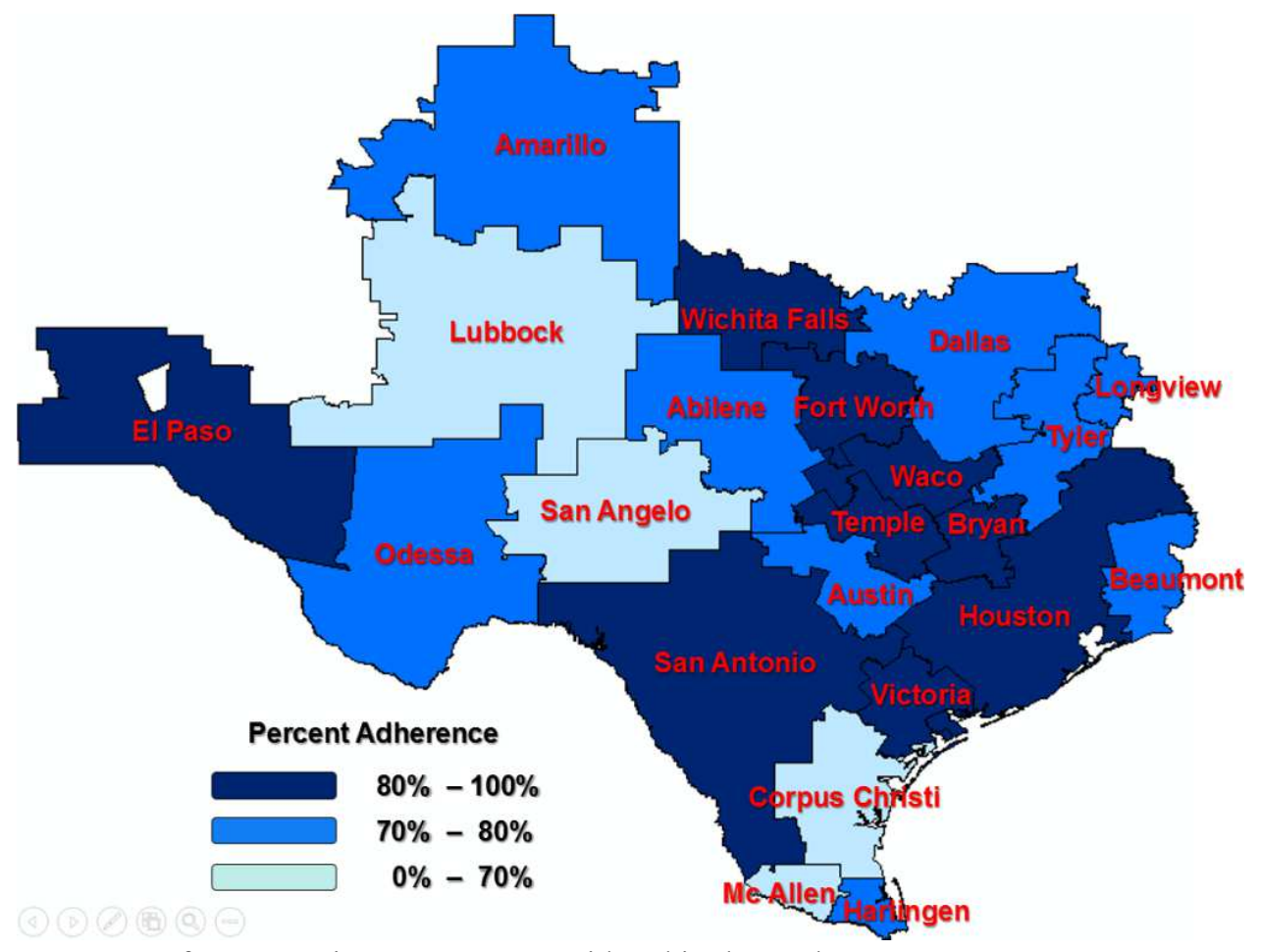

HRRs out of Texas regions were not considered in the study

Figure 3. 90-day persistence among Texas Hospital Referral regions (HRRs)

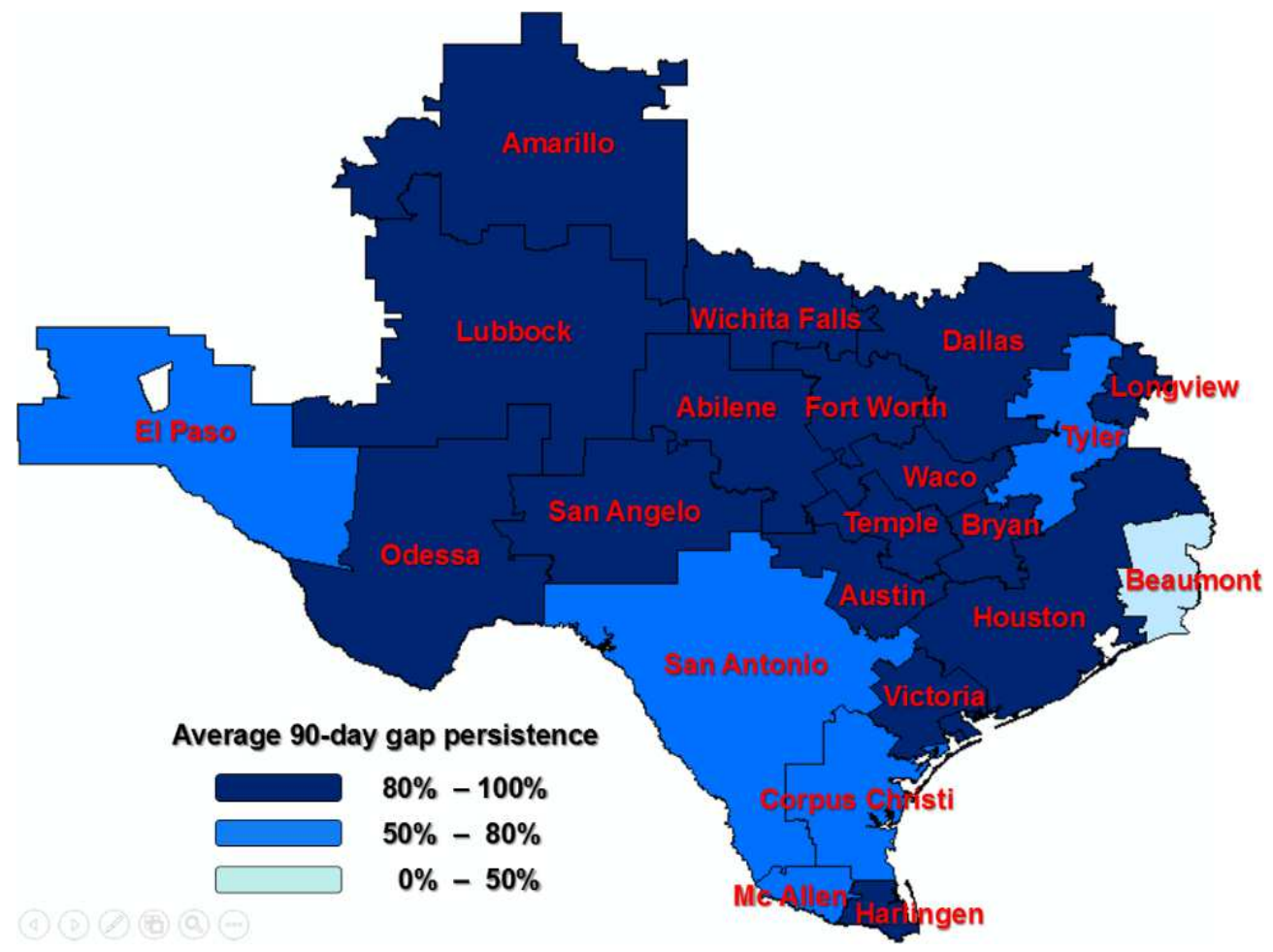

HRRs out of Texas regions were not considered in the study 
Sensitivity analyses were conducted to see whether the 60-day or 180-day gaps in therapy affected the persistence rates across the regions. The median regions of the 60-day gap in therapy persistence rate and the 180day gap in therapy persistence are Tyler (78\%) and Lubbock (94\%), respectively (Appendix Table A). The Texas mapping with HRRs to address variations in persistence of AHT across the regions can be found in the Appendix.

Adherence. In the adjusted regression models for adherence to hormone therapy (Table 3), the patients who received BCS $(\mathrm{p}<0.011)$ or chemotherapy $(\mathrm{p}<0.032)$ were more likely to adhere to the AHT, whereas patients who resided in the places where more non-white population live $(\mathrm{p}<0.0001)$, which had higher rates of poverty $(\mathrm{p}<0.014)$, and more Hispanics or Latinos $(\mathrm{p}<0.009)$ were less likely to adhere to the treatment. The number of outpatient visits $(\mathrm{p}<0.035)$ and days of inpatient stay $(\mathrm{p}<0.04)$ were associated with AHT adherence positively and negatively, respectively. The number of oncologists in the area $(\mathrm{p}<.0001)$ was significant factor of adherence and patients who initiated the hormonal therapy within a year of diagnosis as recommended $(p<.0001)$ were more likely to adhere to the hormone therapy.

Regional variation in adherence. Five out of 22 HRRs in Texas (Brian, El Paso, Longview, Lubbock and San Antonio) had unadjusted rates of AHT adherence that were significantly different from the median regions of Dallas (Table 4). After controlling for other factors, four out of 22 HRRs in Texas had rates of AHT adherence that were significantly different from the median regions of Dallas. Bryan and El Paso remained significant after adjusting other factors and Austin and McAllen became significant in the adjusted model.

Persistence. In the adjusted models for persistence of adjuvant hormonal therapy (Table 3), patients who were diagnosed breast cancer in later year were more likely to continue the hormone therapy $(\mathrm{p}<0.005)$, patients who were further away from the health care services from the provider where they had the index treatment $(\mathrm{p}<0.012)$ and who had more outpatient visits $(\mathrm{p}<0.02)$ were less likely to persist in the treatment. Patients who initiated the hormonal therapy within a year of diagnosis as recommended $(\mathrm{p}<.04)$ were less likely to experiencing more gaps in therapy. The number of hospital admissions $(\mathrm{p}<0.04)$, the number of hospital beds $(\mathrm{p}<0.04)$, and the number of oncology in the area $(\mathrm{p}<0.02)$ were associated with less and more experiencing gaps in therapy, respectively.

Regional variation in persistence. Two regions, Amarillo and Houston, showed statistically significant unadjusted differences compared to median region of Dallas for 90-day gap persistence in therapy (Table 4). In the adjusted regression, three regions, Amarillo, Harlingen, and Odessa were statistically significantly different from the 
median region of Dallas. Amarillo remained significant and Harlingen and Odessa became significant in the adjusted model.

Since gaps in therapy of other durations (60-day and 180-day) have also been used in the literature, we ran sensitivity analyses to see if regional variations in persistence differed by length of the gaps (see Appendix). One region (Amarillo) found to be significantly different compared to median region for average 180-day gap persistence in therapy. No significant differences in regional variation was found using a 60-day gap persistence in therapy.

Table3. Predictors of adherence to and persistence of the adjuvant hormonal therapy

\begin{tabular}{|c|c|c|}
\hline \multirow[t]{2}{*}{ Characteristics } & \multirow{2}{*}{$\begin{array}{c}\text { Adherence } \\
\text { OR (CI) }\end{array}$} & $\begin{array}{c}\text { Persistence of 90-day gap in } \\
\text { therapy }\end{array}$ \\
\hline & & $\mathrm{HR}(\mathrm{CI})$ \\
\hline \multicolumn{3}{|l|}{ Patient-level characteristics } \\
\hline \multicolumn{3}{|c|}{ Surgery (referent: no cancer-directed surgery) } \\
\hline Breast-conserving surgery & $2.04(1.18,3.54)$ & $1.69(0.94,3.04)$ \\
\hline Mastectomy & $1.30(0.73,2.33)$ & $1.42(0.76,2.67)$ \\
\hline \multicolumn{3}{|c|}{ Chemotherapy (referent: no chemotherapy) } \\
\hline Yes & $1.61(1.04,2.48)$ & $1.17(0.95,1.45)$ \\
\hline \multicolumn{3}{|c|}{ Radiation therapy (referent: no radiation therapy) } \\
\hline Yes & $1.10(0.20,6.17)$ & $0.39(0.15,0.97)$ \\
\hline \multicolumn{3}{|l|}{ Year of diagnosis (referent: 2008) } \\
\hline 2009 & $1.53(0.87,2.71)$ & $0.48(0.27,0.85)$ \\
\hline 2010 & $1.18(0.66,2.09)$ & $1.11(0.60,2.05)$ \\
\hline 2011 & $1.54(0.86,2.75)$ & $1.29(0.67,2.48)$ \\
\hline 2012 & $1.54(0.80,2.98)$ & $2.54(1.13,5.74)$ \\
\hline \multicolumn{3}{|c|}{ Therapy initiation (referent: did initiated ATH within 1yr of BC diagnosis) } \\
\hline Not-Initiated & $0.02(0.009,0.04) *$ & $0.87(0.53,0.98)$ \\
\hline \multicolumn{3}{|c|}{ Age at diagnosis, (referent: $<40$ years) } \\
\hline $40-44$ & $2.28(0.81,6.37)$ & $1.25(0.46,3.46)$ \\
\hline
\end{tabular}




$\begin{array}{lll}45-49 & 1.54(0.60,3.98) & 1.43(0.56,3.67) \\ 50-54 & 2.07(0.82,5.23) & 2.57(0.99,6.60) \\ 55-59 & 2.49(0.99,6.30) & 1.98(0.78 .5 .01) \\ 60-64 & 1.12(0.39,3.21) & \mathbf{3 . 4 4}(\mathbf{1 . 1 3}, \mathbf{1 0 . 5 2})\end{array}$

Neighborhood, \% nonwhite (referent: first quartile)

\begin{tabular}{|c|c|c|}
\hline Second quartile & $0.56(0.30,1.02)$ & $0.79(0.39,1.62)$ \\
\hline Third quartile & $2.47(1.27,4.81)$ & $1.41(0.64,3.11)$ \\
\hline Fourth quartile & $1.16(0.57,2.38)$ & $1.87(0.80,4.35)$ \\
\hline Percent Hispanic and Latino population & $0.57(0.39,0.84)$ & $1.03(0.84,1.25)$ \\
\hline
\end{tabular}

Neighborhood, \% more than high school education (referent: first quartile )

$\begin{array}{lcc}\text { Second quartile } & 1.64(0.79,3.39) & 0.54(0.22,1.34) \\ \text { Third quartile } & 1.55(0.67,3.67) & \mathbf{0 . 2 3}(\mathbf{0 . 0 8 , 0 . 7 2}) \\ \text { Fourth quartile } & 1.48(0.57,3.86) & \mathbf{0 . 2 1}(\mathbf{0 . 0 6 , 0 . 7 2})\end{array}$

Neighborhood, \% below poverty level (referent: first quartile )

$\begin{array}{lcc}\text { Second quartile } & \mathbf{0 . 3 4}(\mathbf{0 . 1 6}, \mathbf{0 . 7 0}) & 2.12(0.85,5.30) \\ \text { Third quartile } & \mathbf{0 . 3 2}(\mathbf{0 . 1 3}, \mathbf{0 . 7 8}) & \mathbf{3 . 0 6}(\mathbf{1 . 0 2}, \mathbf{9 . 1 4}) \\ \text { Fourth quartile } & 0.55(0.21,1.43) & 3.27(0.91,11.75) \\ \text { Comorbidity score } & 0.92(0.83,1.02) & 0.98(0.88,1.09) \\ \text { Outpatient visits } & \mathbf{1 . 1 3}(\mathbf{1 . 0 0}, \mathbf{1 . 2 6}) & \mathbf{0 . 8 4}(\mathbf{0 . 7 2}, \mathbf{0 . 9 8}) \\ \text { Inpatient visits } & \mathbf{0 . 8 5}(\mathbf{0 . 7 2}, \mathbf{0 . 9 9 7}) & 0.88(0.75,1.03) \\ \text { Distance to health services facilities } & \text { referent: less than 5 mile) } \\ \text { 5-10 mile } & 0.68(0.38,1.22) & 0.53(0.28,1.03) \\ 10-35 \text { mile } & 0.96(0.55,1.65) & 0.72(0.38,1.34) \\ 35-100 \text { mile } & 1.81(0.93,3.50) & \mathbf{0 . 8 0}(\mathbf{0 . 5 9}, \mathbf{1 . 1 2}) \\ >100 \text { mile } & 1.03(0.48,2.22) & 0.80(0.35,1.81)\end{array}$

Provider-level characteristics 
Total number of hospitals, 2012

Hospital admissions, 2012

Hospital beds, 2012

\section{Area-level characteristics}

Total Subspecialty, 2013

Number of oncology providers in

area

Bold numbers indicate statistically significant results $(P<0.05)$

Bold and asterisk numbers indicate statistically significant results $(P<0.001)$

Table 4. Unadjusted and adjusted odds of receiving AHT by hospital referral region

\begin{tabular}{|c|c|c|c|c|c|}
\hline & \multirow[t]{2}{*}{$\mathbf{N}$} & \multicolumn{2}{|c|}{ Adherence } & \multicolumn{2}{|c|}{ 90-day gap persistence } \\
\hline & & Unadjusted & adjusted & Unadjusted & Adjusted \\
\hline Abilene & 9 & 1.65 & 2.15 & 0.76 & 0.91 \\
\hline Amarillo & 15 & 1.02 & 2.28 & $0.22^{\mathrm{a}}(0.003)^{\mathrm{b}}$ & $0.14(0.02)$ \\
\hline Austin & 57 & 1.56 & $2.94(0.018)$ & 1.70 & 0.99 \\
\hline Beaumont & 9 & 1.17 & 0.86 & 0.33 & 0.57 \\
\hline Bryan & 10 & $5.28(0.008)$ & $6.83(0.02)$ & - & - \\
\hline Corpus Christi & 5 & 2.64 & 7.98 & 0.33 & 0.55 \\
\hline Dallas & 169 & Ref & Ref & Ref & Ref \\
\hline El Paso & 13 & $7.27(0.001)$ & $11.96(0.013)$ & 0.80 & 0.87 \\
\hline Fort Worth & 55 & 0.79 & 0.99 & 1.21 & 0.48 \\
\hline Harlingen & 8 & 0.24 & 0.45 & 0.98 & $3.03(0.005)$ \\
\hline Houston & 165 & 1.14 & 1.09 & $0.50(0.003)$ & 1.05 \\
\hline Longview & 15 & $2.94(0.03)$ & 1.82 & 1.74 & 1.43 \\
\hline Lubbock & 18 & $0.20(0.03)$ & 0.32 & 1.52 & 2.04 \\
\hline McAllen & 12 & 2.64 & $9.25(0.026)$ & 0.48 & 1.15 \\
\hline
\end{tabular}

18 | $\mathrm{P}$ a g e 


$\begin{array}{lccccc}\text { Odessa } & 21 & 1.08 & 3.85 & 2.82 & \mathbf{1 0 . 2 9}(\mathbf{0 . 0 2}) \\ \text { San Angelo } & 2 & 0.01 & 0.01 & - & - \\ \text { San Antonio } & 51 & \mathbf{2 . 0 7 ( \mathbf { 0 . 0 1 } )} & 4.69 & 0.56 & 1.02 \\ \text { Temple } & 1 & 2.64 & 2.52 & - & - \\ \text { Tyler } & 18 & 0.83 & 0.78 & 0.76 & - \\ \text { Victoria } & 1 & - & - & - & 0.46 \\ \text { Waco } & 5 & 2.64 & 4.12 & 0.29 & - \\ \text { Wichita Falls } & 2 & 1.32 & 0.57 & - & \end{array}$

${ }^{\mathrm{a}}$ Bolded coefficient have $\mathrm{p}$-values less than 0.05 .

${ }^{b}$ Numbers in parentheses are $p$-values. For ease of reading, p-values greater than 0.05 are not reported

\section{DISCUSSION}

Our findings explore regional variations in adherence to and persistence of AHT for those with early breast cancer across regions in Texas. We also examine what factors might have associated with those patterns.

We find at least some significant differences in AHT adherence and persistence rates across regions of Texas. Nine regions out of 22 HRRs adhere taking medications and 6 regions out of 22 showed discontinuing of taking the medication with less than 90-day gaps in therapy. 10 regions and 1 region out of 22 discontinued of taking the medication with less than 60-day gaps and 180-day gaps in therapy, respectively. Most of the smaller HRRs have significantly higher or lower rates of treatment adherence and persistence rates relative to the median regions.

The use of AHT varies substantially from one geographical area to another, especially for adherence, with an approximately two-fold difference between the lowest and highest areas. Areas in which the compliance rate is among the lowest quintile should be the focus of the policies or strategies to increase the use of recommended care.

Patient-level factors were found to be significantly associated with the compliance of AHT. For adherence, patients who reside in lower SES areas (the places where more non-white population live, higher rates of poverty, a lower proportion of the population receiving high school education, and more Hispanics or Latinos reside in) have lower probabilities of receiving AHT. Clinical factors including the patients who received BCS or chemotherapy, and the larger number of outpatient visits have positive effect on adherence. These findings are consistent with a 
prior studies [33-35]. For persistence, patients who live in the areas where more non-white population reside and the further distance from the residential area to the health care services from the provider were less likely to persist in the treatment.

For both adherence and persistence, patients who initiated the hormonal therapy within a year of diagnosis as recommended were more likely to adhere and to continue to the hormone therapy. National guidelines and American Society of Clinical Oncology (ASCO) recommend that women with non-metastatic breast cancer should initiate adjuvant hormonal therapy within a year of diagnosis [36, 37]. Initiation of AHT medications and ensuring the continuity of care after the initiation should be emphasized since these interventions would reduce further exacerbation, recurrence.

Variation across geographical areas for adherence and persistence was partially explained by the number of hospital admissions and the number of hospital beds of the provider-level characteristics, and the number of oncologists in the area of the area-level characteristics. However, the larger number of oncologists in the area did not mean that higher adherence rates in this study. This could be due to the role of the patient in making the decision to refill prescription or have a follow up visit. Our data can only capture the patients who refilled their prescription and had a follow-up visit with their providers. We have no information on whether providers may emphasize the importance of taking the medications as prescribed and recommended. Therefore, we cannot test the hypothesis as to whether it is the patients who are primarily responsible for making the decision to get their prescription refilled or to take their medication as recommended, moreover, increased demand for specialist care such as oncologists may not be the most important factor in continuing their AHT for these breast cancer patients.

Our study has several limitations that need to be considered. Because administrative claims data are used in this study, we did not have clinical information, such as hormone-receptor status to justify the appropriateness of the initiation of AHT. However, we applied well-known algorithm that was specifically developed for claims data for identifying incident breast cancer cases [38], this algorithm has been approved of better performance of examining breast cancer cases using claims data. Examining adherence using prescription claims assumes that patients are taking medications as often as they fill prescriptions. Although using pharmacy records is the most accurate and validated estimate of actual medication use in large populations over periods of time [39, 40], future research should address whether patients are actually taking the medication continuously as prescribed for follow-up. 
Finally, since our study population included only women aged less than 65 enrolled in private insurance in Texas, the results may not generalize to patients who have public, or no, coverage or the patients who reside in other states. However, no study has been conducted examining AHT compliance patterns of younger, privately insured women in Texas. This study helps to fill that gap.

In summary, we found substantial variations in the rates of adherence to and persistence with AHT for privately insured women with early breast cancer across the regions in Texas. Patient factors such as socioeconomic status are significantly associated with complying with treatment. System-level strategies, such as oncologists should explicitly recommend women about their medication use, and ask about barriers to compliance of the therapy, especially for those who reside in AHT underuse regions may improve the adherence to and persistence with the AHT and finally reduce further recurrence in patients with breast cancer.

Compliance with Ethical Standards:

Funding: This study was not funded.

Conflict of Interest: no conflict exists: all authors for this study declare that he/she has no conflict of interest. Ethical approval: This article does not contain any studies with human participants performed by any of the authors. 


\section{References}

1. Texas Cancer Registry (www.dshs.texas.gov/tcr) SEER*Stat Database, Mortality - Texas, 1990-2016, statewide, Texas Department of State Health Services (created June 2019)

2. Yung RL, Hassett MJ, Chen K, Gesten FC, Roohan PJ, Boscoe FP et al (2012) Initiation of Adjuvant Hormone Therapy by Medicaid Insured Women With Nonmetastatic Breast Cancer. J Natl Cancer Inst $14: 1102-11$

3. Owusu C, Buist DSM, Field TS, Lash TL, Thwin SS, Geiger AMet al (2008) Predictors of tamoxifen discontinuation among older women with estrogen receptor- breast cancer. J ClinOncol26:549-555

4. Hershman DL, Kushi LH, Shao T, Buono D, Kershenbaum A, Tsai WY et al (2010) Early discontinuation and nonadherence to adjuvant hormonal therapy in a cohort of 8, 769 early-stage breast cancer patients. $\mathrm{J}$ ClinOncol 28:4120-4128

5. France Vrijens, Sabine Stordeur, Koen Beirens, Stephan Devriese, Elizabeth Van Eycken, Joan Vlayen. Effect of hospital volume on processes of care and 5-year survival after breast cancer: A population-based study on 25000 women. The Breast, Volume 21, Issue 3, June 2012, Pages 261-266

6. Anderson RT, Yang T, Matthews SA, Kern T, Mackley HB, Kimmick G, Louis C, Lengerich E, Yao N. Breast cancer screening, area deprivation, and later stage breast cancer in Appalachia: does geography matter? Health Serv Res. 2014; 49:546-67.

7. Birkmeyer JD, Reames BN, McCulloch P, Carr AJ, Campbell WB, Wennberg JE. Understanding of regional variation in the use of surgery. Lancet. 2013; 382:1121-9.

8. Fairfield KM, Lucas FL, Earle CC, Small L, Trimble EL, Warren JL. Regional variation in cancer-directed surgery and mortality among women with epithelial ovarian cancer in the Medicare population. Cancer. $2010 ; 116: 4840-8$.

9. Feinstein AJ, Soulos PR, Long JB, Herrin J, Roberts KB, Yu JB, Gross CP. Variation in receipt of radiation therapy after breast-conserving surgery: assessing the impact of physicians and geographic regions. Med Care. $2013 ; 51: 330-8$.

10. Nattinger AB, Gottlieb MS, Veum J, Yahnke D, Goodwin JS. Geographic variation in the use of breastconserving treatment for breast cancer. N Engl J Med. 1992; 326:1102-7. 
11. Sariego J. Regional variation in breast cancer treatment throughout the United States. Am J Surg. 2008;196: 572-4. doi: 10.1016/j.amjsurg.2008.06.017. pmid:18809065

12. R. Oasteen, G. Steele, H. Menck, et al. Regional differences in surgical management of breast cancer CA Cancer J Clin, 42 (1992), pp. 39-43

13. Yung RL, Hassett MJ, Chen K, Gesten FC, Roohan PJ, Boscoe FP et al (2012) Initiation of Adjuvant Hormone Therapy by Medicaid Insured Women With Nonmetastatic Breast Cancer. J Natl Cancer Inst $14: 1102-11$

14. Owusu C, Buist DSM, Field TS, Lash TL, Thwin SS, Geiger AMet al (2008) Predictors of tamoxifen discontinuation among older women with estrogen receptor- breast cancer. J ClinOncol26:549-555

15. Hershman DL, Kushi LH, Shao T, Buono D, Kershenbaum A, Tsai WY et al (2010) Early discontinuation and nonadherence to adjuvant hormonal therapy in a cohort of 8, 769 early-stage breast cancer patients. J Clin Oncol 28:4120-4128

16. France Vrijens, Sabine Stordeur, Koen Beirens, Stephan Devriese, Elizabeth Van Eycken, Joan Vlayen. Effect of hospital volume on processes of care and 5-year survival after breast cancer: A population-based study on 25000 women. The Breast, Volume 21, Issue 3, June 2012, Pages 261-266

17. Partridge, A. H. (2003). Nonadherence to Adjuvant Tamoxifen Therapy in Women With Primary Breast Cancer. Journal of Clinical Oncology, 21(4), 602-606. doi: 10.1200/jco.2003.07.071

18. Nekhlyudov L, Li L, Ross-Degnan D, Wagner AK (2011) Five-year patterns of adjuvant therapy use, persistence, and adherence among insured women with early- stage breast cancer.

19. Sedjo RL and Devine S (2011) Predictors of non-adherence to aromatase inhibitors among commercially insured women with breast cancer.Breast Cancer Research and TreatmentVolume 125: 191-200

20. Kimmick G, Anderson R, Camacho F, Bhosle M, Hwang W, Balkrishnan R. Adjuvant hormonaltherapy use among insured, low-income women with breast cancer. J ClinOncol. 2009 Jul 20;27(21):3445-51.

21. Balkrishnan R, Rajagopalan R, Camacho FT, Huston SA, Murray FT, Anderson RT. Predictors of medication adherence and associated health care costs in an older population with type 2 diabetes mellitus: a longitudinal cohort study. Clin Ther. 2003;25(11):2958-2971 
22. Owusu C, Buist DSM, Field TS et al (2008) Predictors of tamoxifen discontinuation among older women with estrogen receptor-positive breast cancer. J ClinOncol 26:549-555

23. American Cancer Society. Cancer facts \& figures 2015. Atlanta: American Cancer Society; 2015.

24. Cramer JA, Roy A, Burrell A, Fairchild CJ, et al. Medication Compliance and Persistence: Terminology and Definitions. 2007, International Society for Pharmacoeconomics and Outcomes Research (ISPOR) $1098-3015 / 08 / 4444-47$

25. Neugut AI, HIllyer GC, Kushi LH, LAmerato L, Leoce N, Nathanson DS et al (2012) Non-initiation of adjuvant hormonal therapy in women with hormone receptor positive breast cancer: The Breast Cancer Quality of Care Study (B-QUAL). Breast Cancer Res Treat 134(1): 419-428.

26. Lash TL, Fox MP, Westrup JL, Fink AK, Silliman RA (2006) Adherence to tamoxifen over the five-year course. Breast CancerResearch Treat 99:215-220

27. Barron TI, Connolly R, Bennett K, Freely J, Kennedy J (2007) Early discontinuation of tamoxifen: a lesson for oncologists. Cancer 109:832-839

28. Cluse C, Rey D, Huiart L, BenDiane MK, Bouhnik AD, Berenger C et al (2012) Adjuvant endocrine therapy with tamoxifen in young women with breast cancer: determinants of interruptions vary over time. Annals of Oncology 23: 882-890

29. Charlson, M. E., Pompei, P., Ales, K. L., \& MacKenzie, C. R. (1987). A new method of classifying prognostic comorbidity in longitudinal studies: Development and validation. Journal of Chronic Diseases, 40(5), 373-383.

30. Deyo, R. A., Cherkin, D. C., \& Ciol, M. A. (1992). Adapting a clinical comorbidity index for use with ICD-9-CM administrative databases. Journal of Clinical Epidemiology, 45(6), 613-619.

31. D'Hoore, W., Bouckaert, A., \& Tilquin, C. (1996). Practical considerations on the use of the charlson comorbidity index with administrative data bases. Journal of Clinical Epidemiology, 49(12), 1429-1433.

32. The Darthmouth Atlas of Health Care. Research Methods.http://www.dartmouthatlas.org/tools/faq/researchmethods.aspx.

33. Robert SA, Strombom I, Trentham-Dietz A, Hampton JM, McElroy JA, Newcomb PA, Remington PL. Socioeconomic risk factors for breast cancer: distinguishing individual- and community-level effects. Epidemiology. 2004 Jul; 15(4):442-50. 
34. Kong AL, Yen TWF, Pezzin LE, Miao H, Sparapani RA, Laud PW et al (2011) Socioeconomic and Racial Differences in Treatment for BreastCancer at a Low- Volume Hospital. Ann SurgOncol. 18(11): 32203227

35. Schootman M, Jeffe DB, William GE, and Aft R (2009) The Role of Poverty and Racial distribution in the Geographic Clustering of Breast Cancer Survival Among Older Women: A Geographic and Multilevel Analysis. American Journal of Epidemiology Vol.169, No. 5

36. Burstein HJ, Prestrud AA, Seidenfeld J, Anderson H, Buchholz TA, DavidsonNE, Gelmon KE, Giordano S H, Hudis CA, Malin J, Mamounas EP, RowdenD, Solky AJ, Sowers MR, Stearns V, Winer EP, Somerfield MR, Griggs JJ(2010) American Society of Clinical Oncology clinical practice guideline:update on adjuvant endocrine therapy for women with hormone receptor positive breast cancer. J ClinOncol 28: 3784-3796

37. Ansell D, Grabler P, Whitman S, FerransC, Burgess-Bishop J, Murray LR et al (2009) A community effort to reduce the black/white breast cancer mortality disparity in Chicago. Cancer Causes Control

38. Nattinger AB, Laud PW, Bajorunaite R, Sparapani RA, Freeman JL. An algorithm for the use of Medicare claims data to identify women with incident breast cancer. Health Serv Res 2004; 39:1733-49.

39. Choo PW, Rand CS, Inui TS, et al. Validation of patient reports, automated pharmacy records, and pill counts with electronic monitoring of adherence to antihypertensive therapy. Med Care. 1999;37(9):846-57.

40. Steiner JF, Koepsell TD, Fihn SD, Inui TS. A general method of compliance assessment using centralized pharmacy records. Description and validation. Med Care. 1988;26(8):814-23. 


\section{Appendix}

Table A. Mean AHT persistence by HRR, by length of treatment gap

\begin{tabular}{|c|c|c|c|}
\hline & $\mathrm{N}$ & $\begin{array}{c}\text { 60-day gap } \\
\text { persistence by } \\
\text { HRR }\end{array}$ & $\begin{array}{c}\text { 180-day gap } \\
\text { persistence by HRR }\end{array}$ \\
\hline \multicolumn{4}{|c|}{ Hospital Referral Region } \\
\hline Abilene & 9 & 0.89 & 0.89 \\
\hline Amarillo & 15 & 0.80 & 0.80 \\
\hline Austin & 57 & 0.75 & 0.95 \\
\hline Beaumont & 9 & 0.56 & 0.89 \\
\hline Bryan & 10 & 1 & 1 \\
\hline Corpus Christi & 5 & 0.40 & 1 \\
\hline Dallas & 169 & 0.72 & 0.89 \\
\hline El Paso & 13 & 0.77 & 0.85 \\
\hline Fort Worth & 55 & 0.70 & 0.89 \\
\hline Harlingen & 8 & 0.88 & 1 \\
\hline Houston & 165 & 0.70 & 0.91 \\
\hline Longview & 15 & 0.87 & 1 \\
\hline Lubbock & 18 & 0.83 & 0.94 \\
\hline McAllen & 12 & 0.67 & 0.67 \\
\hline Odessa & 21 & 0.81 & 1 \\
\hline San Angelo & 2 & 1 & 1 \\
\hline San Antonio & 51 & 0.65 & 0.86 \\
\hline Temple & 1 & 0 & 1 \\
\hline Tyler & 18 & 0.78 & 0.83 \\
\hline Victoria & 1 & 1 & 1 \\
\hline
\end{tabular}


Waco

Wichita Falls

*Mean of $\mathrm{TX}=0.69 ; 0.90$

Figure a. 60-day persistence among Texas Hospital Referral regions (HRRs)

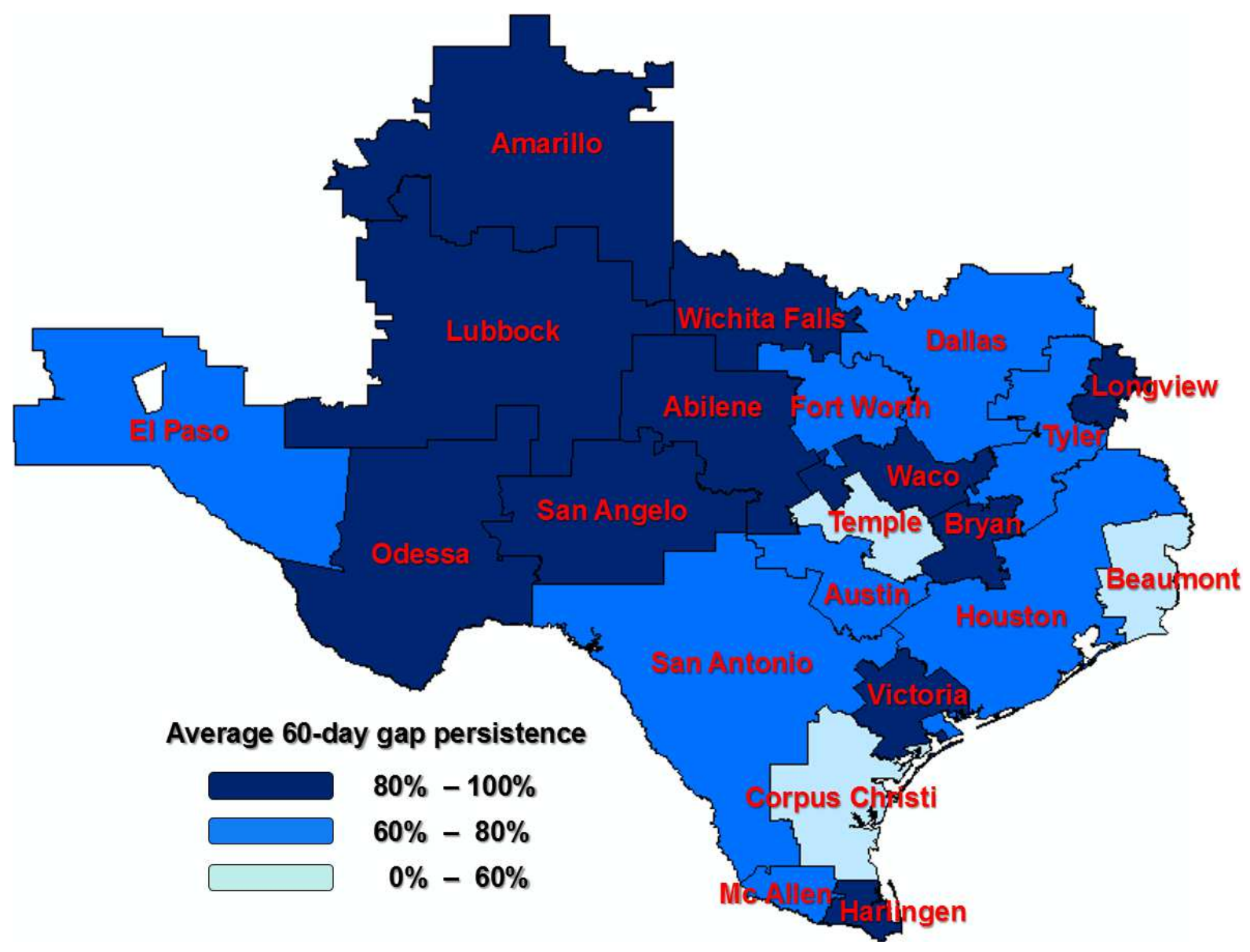

HRRs out of Texas regions were not considered in the study 
Figure b. 180-day persistence among Texas Hospital Referral regions (HRRs)

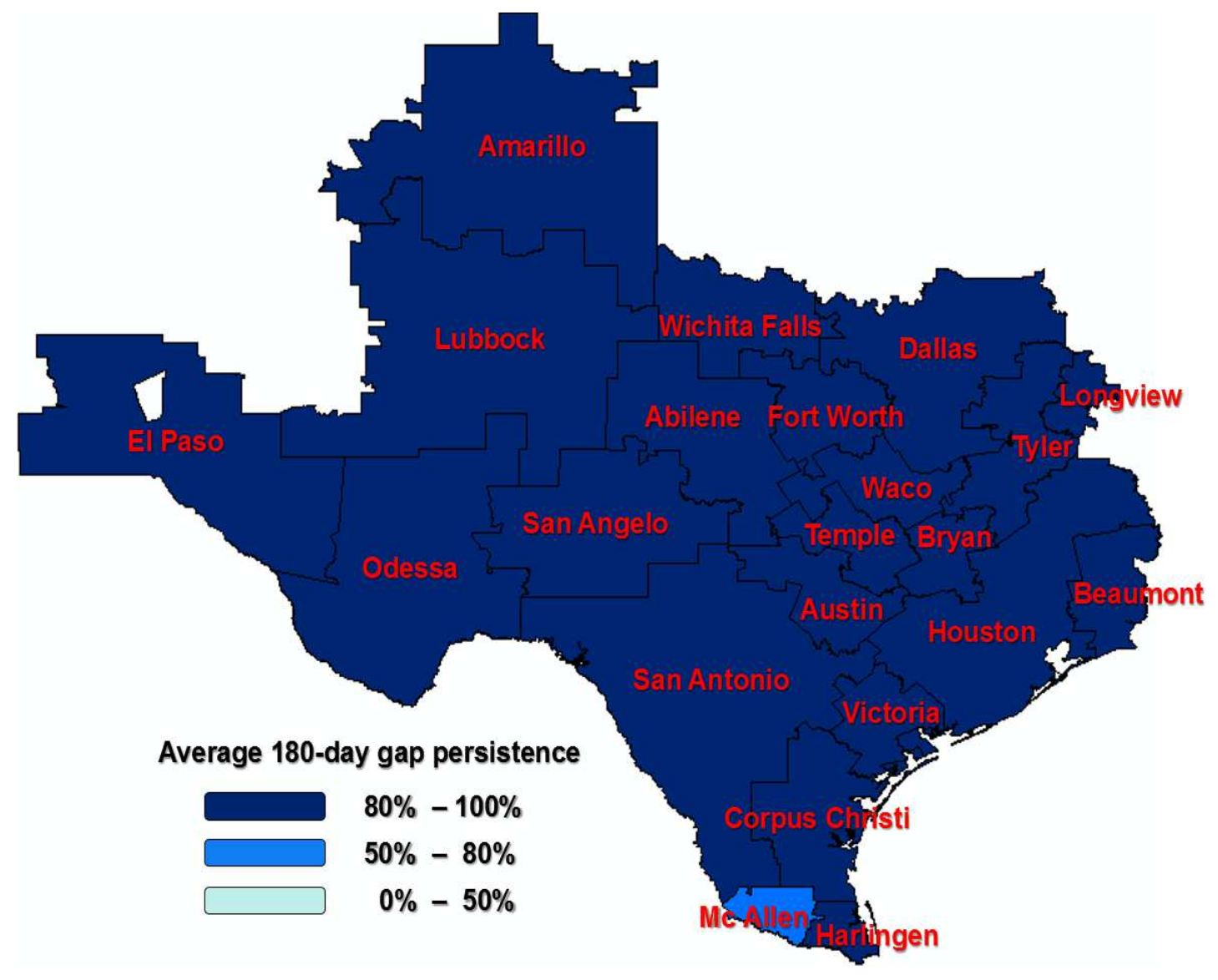

HRRs out of Texas regions were not considered in the study

Table B. Unadjusted and adjusted odds of receiving AHT by hospital referral region (by different days of gaps in therapy)

\begin{tabular}{|c|c|c|c|c|c|}
\hline & \multirow[t]{2}{*}{$\mathrm{N}$} & \multicolumn{2}{|c|}{ 60-day gap persistence } & \multicolumn{2}{|c|}{ 180-day gap persistence } \\
\hline & & Unadjusted & Adjusted & Unadjusted & Adjusted \\
\hline Abilene & 9 & 1.00 & 2.07 & 0.32 & 0.20 \\
\hline Amarillo & 15 & 3.5 & 0.34 & $0.09^{a}(0.006)^{b}$ & $0.03(0.0003)$ \\
\hline Austin & 57 & 0.93 & 1.56 & 2.73 & 1.08 \\
\hline Beaumont & 9 & 5.25 & 0.33 & 0.36 & 0.21 \\
\hline
\end{tabular}




\begin{tabular}{|c|c|c|c|c|c|}
\hline Bryan & 10 & 0.01 & - & - & - \\
\hline Corpus Christi & 5 & 5.25 & 0.79 & - & - \\
\hline Dallas & 169 & 1.18 & 1.51 & 0.83 & 0.21 \\
\hline El Paso & 13 & 0.96 & 3.99 & 0.55 & 0.73 \\
\hline Fort Worth & 55 & 1.42 & 0.75 & 1.11 & 0.18 \\
\hline Harlingen & 8 & 0.78 & 7.46 & - & - \\
\hline Houston & 165 & 2.27 & 0.90 & 1.28 & 0.27 \\
\hline Longview & 15 & 0.44 & 2.19 & - & - \\
\hline Lubbock & 18 & 0.70 & 4.44 & 1 & \\
\hline McAllen & 12 & 1.60 & 4.70 & 0.2 & 0.47 \\
\hline Odessa & 21 & 1.17 & 3.98 & - & - \\
\hline San Angelo & 2 & 0.01 & - & - & - \\
\hline San Antonio & 51 & 2.04 & 1.63 & 0.56 & 0.60 \\
\hline Temple & 1 & - & - & - & - \\
\hline Tyler & 18 & 1 & - & 0.46 & 0.12 \\
\hline Victoria & 1 & 0.01 & - & - & - \\
\hline Waco & 5 & 2.62 & 0.42 & - & - \\
\hline Wichita Falls & 2 & 0.01 & - & - & - \\
\hline
\end{tabular}

${ }^{\mathrm{a}}$ Bolded coefficient have $\mathrm{p}$-values less than 0.05 .

${ }^{b}$ Numbers in parentheses are p-values. For ease of reading, p-values greater than 0.05 are not reported

Table C. Predictors of failure to continue with adjuvant hormonal therapy by length of gap

$\begin{array}{ll}\text { Characteristics } & \text { Duration of gap in therapy }\end{array}$

$$
60 \text { days } 180 \text { days }
$$

\section{Patient-level characteristics}

Cancer Treatment (referent: no mastectomy no BCS no chemo no rad)

$$
\begin{array}{lll}
\text { Mastectomy } & 0.91(0.72,1.16) & 0.89(0.72,1.10)
\end{array}
$$




$\begin{array}{lll}\text { BCS } & 1.04(0.84,1.3) & 1.003(0.82,1.22) \\ \text { Chemotherapy } & \mathbf{1 . 3 ( 1 . 0 4 , \mathbf { 1 . 6 2 } )} & 1.19(0.82,1.22) \\ \text { Radiation therapy } & 0.39(0.14,1.1) & 0.42(0.17,1.01) \\ \text { Year of diagnosis (referent: 2008) } & & \\ 2009 & \mathbf{1 . 3 9}(\mathbf{1 . 0 2}, \mathbf{1 . 8 9}) & \mathbf{1 . 3 7}(\mathbf{1 . 0 4}, \mathbf{1 . 8 0}) \\ 2010 & \mathbf{2 . 3 6}(\mathbf{1 . 7 1}, \mathbf{3 . 2 5}) * & \mathbf{2 . 4 6}(\mathbf{1 . 8 6}, \mathbf{3 . 2 7}) * \\ 2011 & \mathbf{3 . 9 5}(\mathbf{2 . 8 5}, \mathbf{5 . 4 9}) * & \mathbf{3 . 8 0}(\mathbf{2 . 8 2}, \mathbf{5 . 1 1}) * \\ 2012 & \mathbf{6 . 4 9 ( 4 . 5 , 9 . 3 6})^{*} & \mathbf{6 . 6 7}(\mathbf{4 . 7 5}, \mathbf{9 . 3 5})^{*}\end{array}$

Therapy initiation (referent: did not initiated ATH within 1yr of BC diagnosis) Initiated

$0.49(0.31,0.78) * \quad 0.29(0.19,0.44) *$

Age at diagnosis, (referent: $<40$ years)

$\begin{array}{lll}40-44 & \mathbf{0 . 5 8}(\mathbf{0 . 3 4}, \mathbf{0 . 9 9}) & 0.69(0.43,1.11) \\ 45-49 & 0.69(0.43,1.1) & 0.75(0.49,1.14) \\ 50-54 & 0.74(0.47,1.18) & 0.69(0.45,1.03) \\ 55-59 & 0.77(0.48 .1 .23) & 0.77(0.51 .1 .17) \\ 60-64 & 0.8(0.48,1.34) & 0.76(0.48,1.22)\end{array}$

Neighborhood, \% nonwhite (referent: $<10 \%$ )
$10-24 \%$
$1.38(0.99,1.89)$
$1.37(1.03,1.82)$
$25-50 \%$
$1.31(0.89,1.93)$
$1.30(0.91,1.84)$
$\geq 50 \%$
$1.71(1.03,2.84)$
$1.35(0.86,2.13)$
Percent Hispanic and Latino population
$0.94(0.76,1.16)$
$1.01(0.84,1.22)$
Neighborhood, \% less than high school education (referent: $<25 \%$ )
$\geq 25 \%$
$0.86(0.64,1.16)$
$0.88(0.67,1.16)$

Neighborhood, \% below poverty level (referent: $<20 \%$ )
$\geq 20 \%$
$1.21(0.90,1.62)$
$1.12(0.86,1.48)$
Comorbidity
$0.95(0.90,1.0)$
$0.96(0.92,1.006)$
Outpatient visits
$0.99(0.91,1.09)$
$1.01(0.94,1.09)$
Inpatient visits
$0.98(0.91,1.07)$
$0.93(0.93,1.07)$ 


$\begin{array}{lrc}\begin{array}{l}\text { Distance to health services facilities (referent: less than } 5 \text { mile) } \\ \text { 5-10 mile }\end{array} & 0.67(0.49,0.91) & \mathbf{0 . 7 1}(\mathbf{0 . 5 4}, \mathbf{0 . 9 4}) \\ & 0.80(0.62,1.04) & 0.92(0.72,1.16) \\ 10-35 \text { mile } & 0.78(0.56,1.09) & 0.89(0.66,1.19) \\ 35-100 \text { mile } & 0.82(0.57,1.19) & 0.93(0.66,1.30) \\ >100 \text { mile } & \end{array}$

\section{Provider-level characteristics}

Total number of hospitals, 2012

Hospital admissions, 2012

Hospital beds, 2012

\section{Area-level characteristics}

Total Subspecialty, 2013

$$
0.99(0.996,1.002)
$$

$0.99(0.998,1.001)$

Number of oncology providers in area $\quad 0.99(0.997,1.001) \quad 0.99(0.998,1.003)$

Bold numbers indicate statistically significant results $(P<0.05)$

Bold and asterisk numbers indicate statistically significant results $(P<0.001)$ 


\section{Figures}

Identified women 18 years and older with at least one diagnosis of breast cancer between July 2008 and December 2012.

$$
\mathrm{N}=2,656
$$

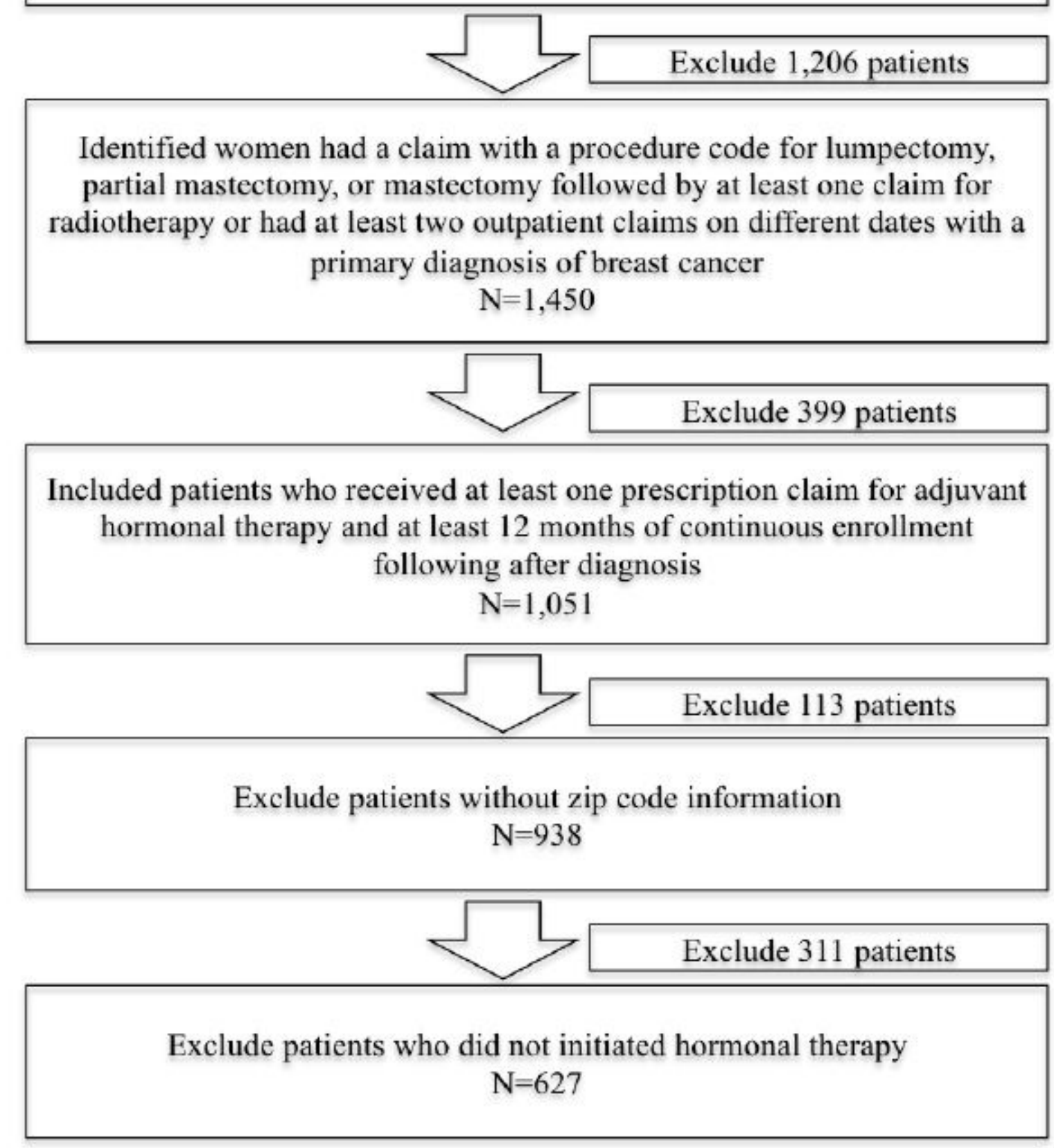

Figure 1

Step of Inclusion/Exclusion Criteria 


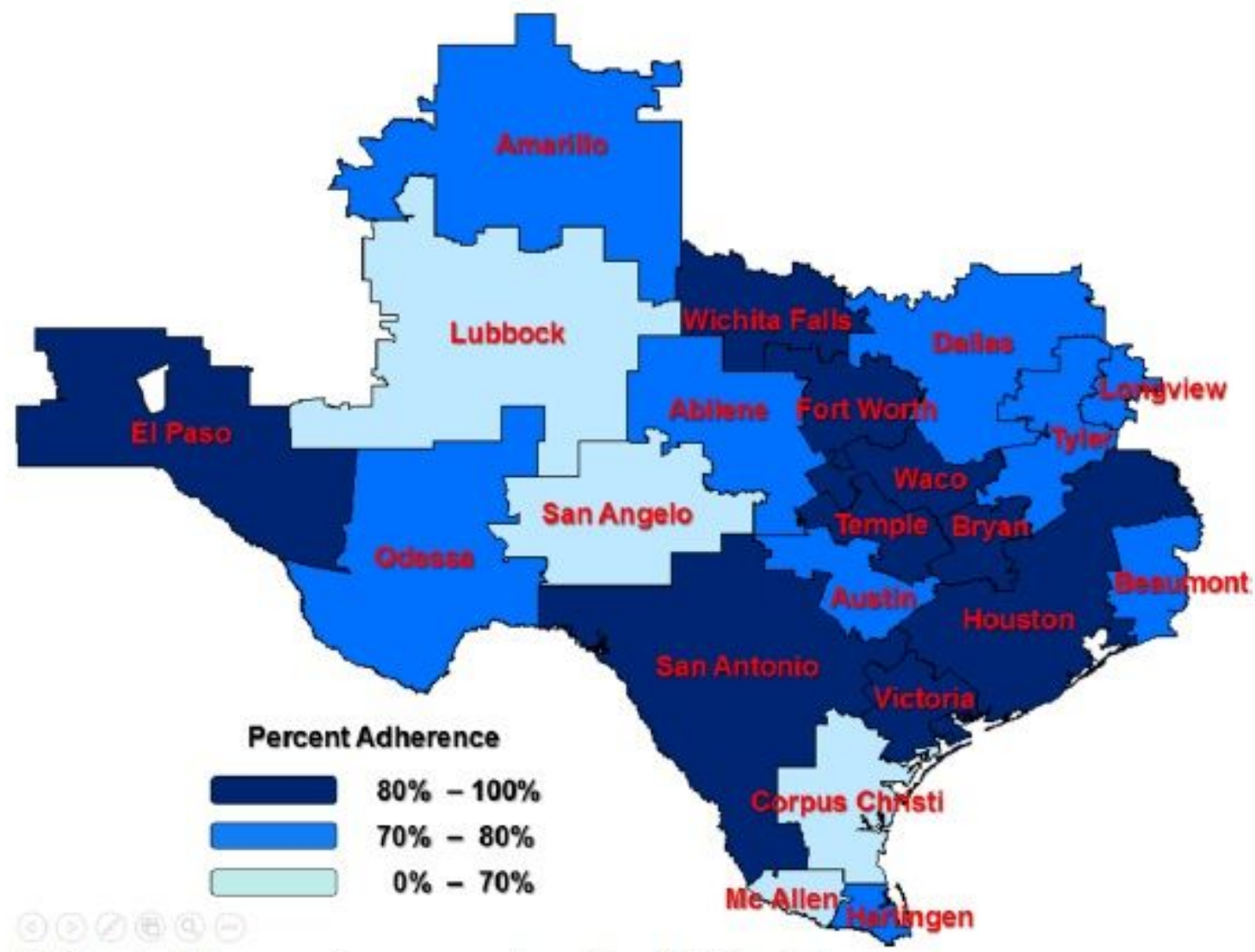

HRRs out of Texas regions were not considered in the study

Figure 2

Adherence among Texas Hospital Referral regions (HRRs) 


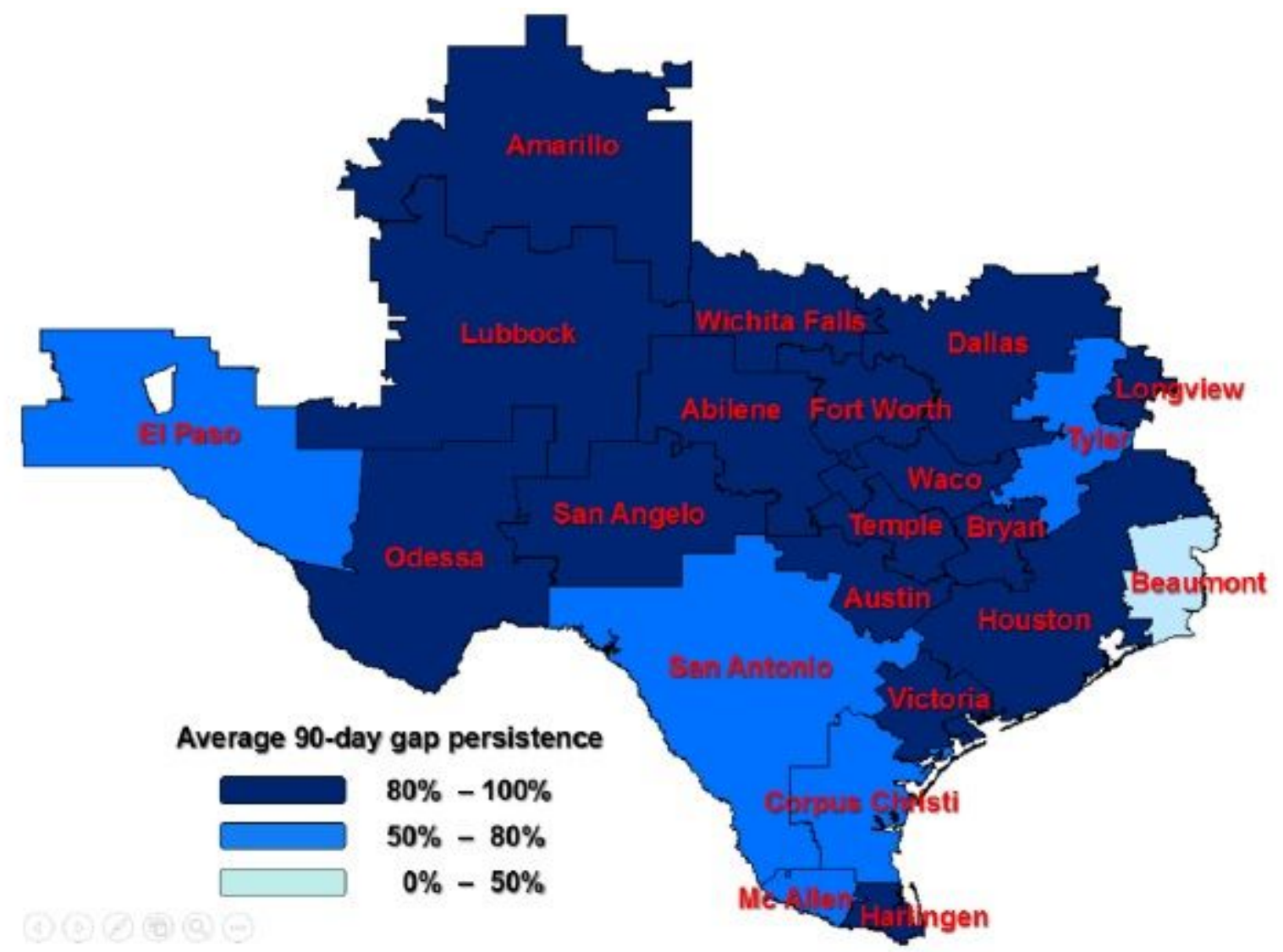

HRRs out of Texas regions were not considered in the study

Figure 3

90-day persistence among Texas Hospital Referral regions (HRRs) 